This is an author produced version of a paper published in Applied Animal Behaviour Science. The paper has been peer-reviewed and proof-corrected, but does not include the journal pagination.

Citation for the published paper:

Hultgren, J., Wiberg, C., Berg, C., Cvek, K., Lunner Kolstrup, C., 2014. Cattle behaviours and stockperson actions related to impaired animal welfare at Swedish slaughter plants. Applied Animal Behaviour Science 152, $23-37$.

doi: 10.1016/j.applanim.2013.12.005

http://dx.doi.org/10.1016/j.applanim.2013.12.005

Access to the published version may require journal subscription.

Published with permission from: Elsevier

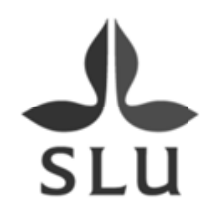

Epsilon Open Archive http://epsilon.slu.se 


\title{
Cattle behaviours and stockperson actions related to impaired animal welfare at Swedish slaughter plants
}

\author{
Jan Hultgren ${ }^{\mathrm{a}, *}$, Sofia Wiberg ${ }^{\mathrm{a}}$, Charlotte Berg ${ }^{\mathrm{a}}$, Katarina Cvek $^{\mathrm{b}}$, \\ Christina Lunner Kolstrup ${ }^{c}$
}

\author{
${ }^{*}$ Corresponding author. Tel.: +46 511 67103. E-mail address: jan.hultgren@slu.se (J. Hultgren) \\ ${ }^{a}$ Department of Animal Environment and Health, Swedish University of Agricultural Sciences, PO \\ Box 234, SE-532 23 Skara, Sweden \\ ${ }^{\mathrm{b}}$ Department of Clinical Sciences, Swedish University of Agricultural Sciences, PO Box 7054, SE-756 \\ 51 Uppsala, Sweden \\ ${ }^{\mathrm{c}}$ Department of Work Science, Business Economics and Environmental Psychology, Swedish \\ University of Agricultural Sciences, PO Box 88, SE-230 53 Alnarp, Sweden
}

\begin{abstract}
At a slaughter plant, cattle are sometimes exposed to rough handling which may reduce animal welfare (AW). In an observational study at four Swedish commercial slaughter plants, AW-related behaviours of cattle and actions of abattoir stockpersons handling the same animals were recorded simultaneously. The objective was to estimate the occurrence of different behaviours and actions related to negative AW during driving and stunning at largescale cattle abattoirs, assess associations between such behaviours and actions, and analyse differences between plants and animal categories (dairy cows, beef cows, adult bulls and heifers/bullocks). Direct continuous observations of focal animals were made using laptops either in a section of the driving race to the stun box (132 animals) or in the stun box (313 animals), generating a total of $14.5 \mathrm{~h}$ of observations. The animals were stunned using a penetrating captive bolt gun or a rifle. Counts per animal of 14 behaviours and 16 stockperson actions were calculated. Sixteen percent of the observed animals displayed total behaviour counts $>5$ in the driving race, and $2 \%$ did so in the stun box; 32 and $8 \%$ of the observed animals received total counts $>5$ of stockperson actions in the race and stun box, respectively. We estimated that two-thirds of the animals were processed without displaying/receiving any of the behaviours/actions associated with severely negative AW. AW scores were acquired by adding together all observed behaviour counts (and action counts, separately) weighted by expert-assessed ratings denoting the degree of impaired AW. Spearman rank correlation was used to analyse associations between behaviour counts, action counts and AW scores. Only three moderate to strong correlations $(\rho \geq 0.4, P \leq 0.001)$ between single behaviours/actions were found ("slapping rear" and "slapping front"; "prodding" and "shouting"; and "prodding" and "beating rear" in the driving race). The correlation between AW scores based on behaviours and actions was statistically significant but rather weak both in the driving race ( $\rho$ $=0.37, P<0.0001)$ and stun box $(\rho=0.22, P=0.0002)$. The effects of slaughter plant and animal category on behaviour counts and AW scores were estimated using standard or zeroinflated negative-binomial regression. The risks of most behaviours related to negative AW differed considerably between plants. In the stun box, adult bulls had a 2.5 times higher risk of "struggling-kicking" $(P=0.016)$ and a 2.0 times higher risk of displaying "backingturning" $(P=0.016)$ than had dairy cows, indicating poorer welfare for the bulls.
\end{abstract}

Keywords: Abattoir; Cattle; Driving; Human-animal interaction; Slaughterhouse; Stockperson; Stunning 


\section{Introduction}

Cattle destined for meat production usually spend either a few hours or a whole night at a slaughter plant before they are killed. Although this is a comparatively short period of their lives, it can have a large influence on animal welfare (AW), which draws attention from the public and competent authorities. At a slaughter plant, cattle are exposed to a number of stressful factors, such as contact with unfamiliar conspecifics, loud noise, odours, painful shocks from electric goads, and hard blows from other animals, stockpersons or equipment. How an animal reacts to such stressors depends on a number of different internal and external determinants, for example breed, age and previous experiences of human handling (Probst et al., 2012, 2013). Stockperson attitudes and actions will influence the animals' pre-slaughter stress levels and welfare (Coleman et al., 2003; Hemsworth, 2003; Hemsworth and Coleman, 1998; Hemsworth et al., 2011). Animal stress in connection with slaughter can also reduce meat quality (Warner et al., 2007), thus causing direct costs to the industry. There are only a few previous studies of animal and stockperson interactions at Swedish slaughter plants, the most recent by Atkinson et al. (2013).

In Sweden, about 450,000 cattle are slaughtered annually (Swedish Board of Agriculture, 2013). The slaughter plants vary considerably in size and throughput. Of a total of approximately 60 Swedish cattle abattoirs in 2011, 16 major plants each processed 6100 to 109,000 head per year, representing $93 \%$ of all Swedish slaughter cattle (pers. comm., $\AA$. Rutegård, Swedish Meat Industry Association, 2012). The facilities also vary in the design of lairage areas, driving races and stun boxes, as well as in the stunning methods applied - all possible determinants of AW. Several large plants are relatively old and some basic designs are problematic. Poor lighting, slippery floors or steep slopes in the driving races have direct negative effects on the animals (Grandin, 2007). The design of a slaughter plant can also have an indirect effect on AW, by counteracting or discouraging the stockpersons from optimal actions towards the animals. For instance, some constructions make it difficult or even impossible to use the animal's flight zones for driving them (Grandin, 1997). Suboptimal design of driveways can also make the animals unwilling to enter the stun box, demanding forceful driving (Bourguet et al., 2011; Grandin, 2007).

The objective of the present study was to describe cattle behaviours and stockperson actions commonly related to poor AW at commercial slaughter plants in Sweden. We aimed to estimate the occurrence of different behaviours/actions during driving and stunning, to assess associations between them, and to analyse differences between plants and between animal categories.

\section{Material and methods}

This study was approved by the Swedish Regional Ethical Review Board for studies involving humans and the Swedish Regional Ethics Committee for animal experiments. For ethical and confidentiality reasons, the slaughter plants are not described in detail. The study was part of a Swedish project with the overall aim to investigate relationships between AW and staff well-being at the slaughter of cattle, compared with euthanasia of laboratory rats. Project data collection also included questionnaires and interviews.

\subsection{Studied slaughter plants and stockpersons}

Of 63 Swedish cattle slaughter plants registered by the Swedish National Food Agency in 2009, all 16 plants processing more than 4600 cattle per year were asked about their interest in joining the study. Initially, four plants suitable for the study, as judged by size, location and 
willingness to participate, were approached and visited. Two of them chose to participate. Using the same size criterion, two additional plants were contacted and agreed to participate, resulting in four studied plants with a wide geographical spread in Sweden.

All animals were unloaded from the transport vehicle at arrival and kept in indoor lairage before slaughter. Lairage consisted of either group pens for two to 10 animals or individual pens arranged as sections of the driving race with vertical sliding doors between them. Three of the plants routinely kept cattle in lairage overnight.

Driving race design and length varied between abattoirs. Two plants had a single file race all the way from lairage to the stun box. At a third plant the first part of the driving race was wider, with a single file race in the last $10 \mathrm{~m}$ before the stun box. At the fourth plant, the race consisted of an old cattle housing facility, a holding pen for five or six animals and two parallel single file races leading to the stun box (Fig. 1). The floors were solid or slatted concrete, in one case with a textured rubber mat in the last part before the stun box, and in another case with sawdust litter. The floor in the last part of the race sloped slightly upwards in three of the plants. Three plants had solid walls $1.5 \mathrm{~m}$ high (one starting $0.15 \mathrm{~m}$ above floor level) in the driving races. One plant had metal bars, but with solid walls up to $0.6 \mathrm{~m}$ above floor level.

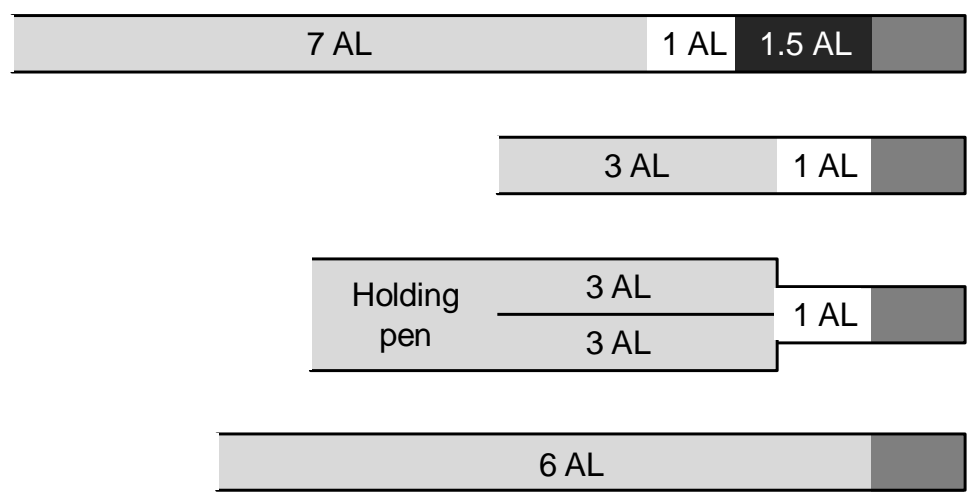

Fig. 1. Schematic representation of observed sections of the driving races (light grey) and stun boxes (dark grey, and black in one plant equipped with a forcing gate), as well as unobservable sections (white), at four studied Swedish cattle slaughter plants; length of each section is expressed as number of animal lengths $(1 \mathrm{AL}=2.4 \mathrm{~m})$.

Three plants had fixed walls in the stun box and a stockperson drove the animals manually all the way into the stun box using his body, hands and various tools. The fourth plant had a hydraulic forcing gate, entering the race from one side and moving horizontally behind the animal to move it the last few metres into the stun box. This gate also worked as an adjustable back wall of the stun box. The other three plants had hydraulic vertically-sliding tailgates at the entrance of the box. In one plant, one of the sides of the stun box was sloping slightly, to make the animal fall out of the box after stunning. For the same reason, there was also a small gradient of the floor in the stun box at two plants. Two stun boxes had solid concrete flooring and two were equipped with rubber mats. Two facilities had bars on top of the stun box to keep struggling animals in the box and protect the staff from being kicked or gored.

Two slaughter plants used a standard penetrating cartridge-powered captive bolt gun, one a penetrating pneumatic captive bolt gun and one a two-handed rifle with free bullet. The plant with the pneumatic gun restrained the head of the animals during stunning, while the others did not.

During observations, the stockpersons always worked the animals from outside the race or box. Normally, only one person worked each animal in the stun box; however, at one of the 
plants, the number of observed stockpersons per processed animal was sometimes two or three.

\subsection{Observations}

Behavioural observations were made in 2011 within regular working hours (06:00 to 16:00 h) during 3 consecutive days, and at one plant during 2 additional days 2 months later, resulting in a total observation time of $14 \mathrm{~h} 33 \mathrm{~min}$. The timing of observations was based on practical research considerations, rather than the convenience of the slaughter plants.

Animals and the stockpersons handling them were observed simultaneously using continuous observations. Focal animals were randomly selected among animals entering the observation area and categorised as dairy cows, beef cows, adult bulls or heifers/bullocks. At each recording session, one researcher (always the same person) observed focal animals and another one observed stockpersons simultaneously (task rotated between three different persons according to their availability and corresponding to $39 \%, 36 \%$ and $25 \%$ of the focal animals). The observers were trained before the start of observations using video clips on a desktop computer, but it was not possible to estimate the agreement between and within observers.

Recording of behaviours and actions was made using the Interact software (version 9.1.2; Mangold Int. GmbH, Arnstorf, Germany) on two portable laptop computers (Eee PC 1001PX, ASUSTeK Computer Inc., Taipei, Taiwan) equipped with Windows ${ }^{\circledR} 7$ Starter (Microsoft Corp., Redmond, WA, USA), one for animal and one for stockperson observations, and in both cases harnessed onto the chest of the observer. The computer clocks were synchronised at the start of each observation session.

Observations were made at two different steps of the slaughter process: in the last part of the driving race from lairage to the stun box, and from driving into the stun box until the first shot with the stunning weapon (some animals were shot more than once). For practical reasons, different animals were observed in the driving race and stun box. The observers were positioned next to each other where they had the best possible view of the animals and stockpersons, moving around as needed without disturbing the work. At each slaughter plant, imaginary start and stop positions for observations were defined before recording commenced. These positions were chosen so as to allow continuous monitoring of as much as possible of the driving race where all cattle passed, taking design and routines of each plant into consideration. An observation started as the nose of the focal animal passed the start position and ended as the rump of the animal passed the stop position or the animal was shot (first time). At three plants, solid walls and gates made it impossible to see a section of the race between the driving race and the stun box, approximately one animal long, and this section was therefore excluded (Fig. 1).

Animal behaviours to record (Table 1) were selected as measures of impaired AW identified previously (Welfare Quality, 2009). "Crowding" and "eliminating" were not recorded in the stun box. The choice of AW-related stockperson actions to be recorded (Table 2) was based on previous research and experience. Five experts, selected for ample experience and skills in cattle slaughter and AW assessment, assigned individually an AW rating of 1 (mild), 2 (moderate), or 3 (severe) to each behaviour and stockperson action, denoting the degree of impaired AW or negative impact on AW, respectively. The agreement between experts as judged by Fleiss' kappa was fair to moderate $(\kappa=0.47, P<0.001$ for 13 animal behaviours; $\kappa=0.23, P<0.001$ for 15 stockperson actions). The medians among the experts were used as final ratings. "Exploring" and "speaking" were considered neutral and were assigned a rating of 0 . The number of shots with the stunning weapon was also recorded. 


\subsection{Statistical analysis}

Behavioural data were edited and analysed using JMP® (version 9; SAS Institute Inc., Cary, NC, USA), ExcelTM (version 2010; Microsoft Corp., Redmond, WA, USA) and Stata/IC (version 12; StataCorp LP, College Station, TX, USA). The count of each type of recorded behaviour and stockperson action was calculated for each focal animal. Due to the divergent stun box design and the forcing gate used for moving animals into the box at one slaughter plant, recordings of "gate hitting" were not included in the analysis of stun box data from that plant.

For each animal and for the driving race and stun box separately, the counts of all recorded animal behaviours were multiplied by the respective AW ratings and added together, resulting in a weighted count sum, denoted AW score, based on behaviours (AWBEH), with higher values indicating more negative AW. A corresponding AW score was calculated from the counts of all recorded stockperson actions (AWACT).

Spearman rank correlation was used to investigate within-animal associations between counts of behaviours and actions with an AW rating of at least 2 and being shown/received by at least five animals (excluding "exploring" and "speaking"), as well as AWBEH and AWACT, in the driving race and stun box separately. Correlations with a Spearman $|\rho| \geq 0.4$ and $P \leq 0.001$ were considered to indicate a moderate to strong association.

Behaviour counts, AWBEH and AWACT were analysed using negative binomial regression, assessing the effect of abattoir and animal category on the risk of displaying behaviours and of poor AW, respectively. This type of regression is used to model count data when there is evidence of overdispersion, i.e. when data do not follow a Poisson distribution, which may be due to heterogeneity in the study population. To restrict the number of models and achieve sufficient counts, the behaviours were aggregated in four groups analysed separately for driving race and stun box: (1) "backing-turning" ("moving backwards" or "turning"); (2) "slipping-falling" ("minor slipping", "major slipping" or "falling"); (3) "struggling-kicking" ("minor struggling", "major struggling" or "kicking"); and (4) "any behaviour" ("backing-turning", "slipping-falling", struggling-kicking”, "crowding”, "running", "freezing", "vocalising" or "eliminating", i.e. any of the recorded behaviours, excluding "exploring"). The counts in the four behaviour groups, AWBEH and AWACT were modelled for driving race and stun box separately, resulting in a total of 12 models. Effects of both slaughter plant and animal category (four categories each) were included if possible, but one of them was excluded if necessary to make the model estimable. In all models, the slaughter plants were numbered consistently 1 to 4 . Dairy cows and plant 1 were arbitrarily chosen as base levels, to which other animal categories and plants were compared. It was not possible to estimate the interaction between plant and animal category because some combinations were missing. Initially, zero-inflated models were constructed, and the likelihood-ratio based Vuong test (Vuong, 1989) was applied, retaining the zeroinflated approach only if the test was significant $(P \leq 0.05)$. Zero-inflated negative binomial regression is used to model overdispersed count data with an excessive number of zeros. Theoretically, a zero count can occur for two distinct reasons; either chance alone or because a higher count for some reason is not possible ("certain zero" cases). Chance alone will result in a standard probability distribution such as the negative binomial, while certain zeros will produce a zero-inflated distribution. In Stata, a separate logit model is generated for the "certain zero" cases, predicting whether or not an animal would be in this group, and the Vuong test can be used to compare the zero-inflated model to a standard negative binomial model. Thus, zero-inflated negative binomial regression (Stata/IC zinb command) was used for "slipping-falling" in the driving race, for "any behaviour" in the stun box, and for AWBEH in the stun box, while standard negative binomial regression (nbreg command) was 
used in the remaining models. Dispersion was parameterised as $\exp (\mathrm{xb}+$ offset $)$, where $\mathrm{xb}$ was the expected mean and offset was $\ln$ (total observation time) for each animal. In the zeroinflated models, animal category was used to predict certain zeros with a logit inflation model.

\section{Results}

A total of 445 cattle and 15 male stockpersons were observed (162, 138, 105 and 40 animals and five, five, three and two stockpersons, respectively, at the four slaughter plants). Different stockpersons worked with driving, stunning and sticking animals at two plants, while one person carried out at least two of these tasks at the two other plants. At one plant, only one person worked with driving animals, while the same work was divided between several persons at the other plants. At three of the plants, only one person was stunning during a single day, while several persons were observed stunning animals during the same day at the fourth plant. As a result, five of the stockpersons were observed both in the driving race and stun box, seven only in the race and three only in the stun box. Recordings of stockperson actions were missing for 11 animals in the driving race $(1,3,1$ and 6 animals per plant, respectively) and 30 animals in the stun box (1, 6, 13 and 10 animals per plant, respectively).

\subsection{Driving race}

In the driving race, 132 focal animals were observed (60,34, 25 and 13 animals at the four slaughter plants). The total observation times in the driving race at the four plants were 204, 168, 113 and 105 min, respectively, resulting in mean (min.-median-max.) observation times of 15.7 (0.4-7.8-72), 4.9 (0.2-4.3-22), $4.2(0.4-2.7-12)$ and $1.9(0.1-1.4-10)$ $\mathrm{min} /$ animal.

The behaviours observed in the highest number of animals were "moving backwards" and "crowding" (Table 1). The maximum behaviour count per animal was 55, displayed by one animal, and 38 animals displayed none of the recorded behaviours (excluding "exploring"). There were no cases of "falling" in the driving race.

Twelve stockpersons were observed in the race. One stockperson driving 51 animals (39\% of all animals observed) displayed $46 \%$ to $84 \%$ of the actions "shouting", "hitting rear", "hitting front", "beating rear", "beating front", "gate hitting" and "prodding". Another stockperson, driving $9 \%$ of the animals, performed $57 \%$ and $48 \%$ of the "touching rear" and "touching front", respectively. The actions displayed towards the highest number of animals were "speaking", "touching rear" and "hitting rear" (Table 2). Three animals each received 16 to 24 "slapping rear/front" or "beating rear/front", and three animals were prodded 10 to 15 times each. "Booting", "tail twisting" or repeated use of an electric goad was observed in 12 animals in the driving race. The maximum action count per animal was 112 , received by one animal, and 45 animals received none of the recorded actions (excluding "speaking").

Nineteen animals (16\%) displayed no recorded behaviours and had no recorded stockperson actions directed towards them, 10 animals (8\%) displayed no behaviours but received one to 15 stockperson actions, and 26 animals (21\%) received no stockperson actions but displayed one to 24 behaviours (excluding "exploring" and "speaking"). The percentages of animals displaying different behaviours and receiving different stockperson actions are shown in Figs. 2 and 3. 
Table 1

Percentage of animals with different counts of recorded behaviours in the driving races $(n=132)$ and stun boxes $(n=313)$ of four Swedish cattle slaughter plants in 2011.

\begin{tabular}{|c|c|c|c|c|c|c|c|c|c|c|c|c|c|c|}
\hline \multirow[t]{2}{*}{ Behaviour } & \multirow[t]{2}{*}{ Description } & \multirow{2}{*}{$\begin{array}{l}\mathrm{AW} \\
\text { rating }^{\mathrm{a}}\end{array}$} & \multicolumn{6}{|c|}{ Count in driving race } & \multicolumn{6}{|c|}{ Count in stun box } \\
\hline & & & 0 & 1 & 2 & $3-5$ & $>5$ & Max. ${ }^{b}$ & 0 & 1 & 2 & $3-5$ & $>5$ & Max. \\
\hline Crowding & $\begin{array}{l}\text { Is prevented by other animals from moving } \\
\text { forwards or backwards }\end{array}$ & 2 & 67 & 15 & 8.3 & 8.3 & 1.5 & 7 & - & - & - & - & - & - \\
\hline $\begin{array}{l}\text { Moving } \\
\text { backwards }\end{array}$ & Moves at least two steps backwards & 2 & 46 & 27 & 11 & 13 & 3.0 & 18 & 80 & 14 & 3.5 & 2.6 & 0.32 & 6 \\
\hline Turning & Turns or attempts to turn in race & 2 & 91 & 6.8 & 0.76 & 1.5 & 0 & 3 & 94 & 3.8 & 1.6 & 0.32 & 0 & 3 \\
\hline Running & Runs forward & 2 & 97 & 3.0 & 0 & 0 & 0 & 1 & 98 & 2.2 & 0 & 0 & 0 & 1 \\
\hline Minor slipping & Feet slide, but continues to walk forward & 1 & 89 & 6.8 & 3.0 & 0.76 & 0 & 3 & 92 & 7.7 & 0.32 & 0 & 0 & 2 \\
\hline Major slipping & $\begin{array}{l}\text { Feet slide and stops walking, but only hooves or } \\
\text { legs in contact with floor }\end{array}$ & 2 & 92 & 5.3 & 1.5 & 0.76 & 0 & 4 & 95 & 3.5 & 0.96 & 0.32 & 0 & 4 \\
\hline Falling & Body in contact with floor & 3 & 100 & 0 & 0 & 0 & 0 & 0 & 99 & 0.64 & 0 & 0 & 0 & 1 \\
\hline Kicking & Kicks with hind leg towards stockperson & 2 & 95 & 3.0 & 0.76 & 0 & 0.76 & 6 & 99 & 0.96 & 0 & 0.32 & 0 & 3 \\
\hline $\begin{array}{l}\text { Minor } \\
\text { struggling }\end{array}$ & Repeatedly trips, moves from side to side or kicks & 2 & 99 & 0.76 & 0 & 0 & 0 & 1 & 83 & 14 & 2.6 & 0.64 & 0 & 3 \\
\hline $\begin{array}{l}\text { Major } \\
\text { struggling }\end{array}$ & $\begin{array}{l}\text { Repeatedly throws itself against wall, jumps, tosses } \\
\text { head, shivers or pants }\end{array}$ & 3 & 99 & 0.76 & 0 & 0 & 0 & 1 & 95 & 2.9 & 1.9 & 0 & 0 & 2 \\
\hline Freezing & $\begin{array}{l}\text { Stops moving and refuses to walk despite repeated } \\
\text { attempts by stockperson }\end{array}$ & 2 & 93 & 5.3 & 0.76 & 0.76 & 0 & 4 & 98 & 1.6 & 0 & 0 & 0 & 1 \\
\hline Vocalising & Makes vocal sound & 2 & 86 & 6.1 & 3.0 & 0.76 & 4.5 & 49 & 93 & 4.5 & 0.64 & 1.6 & 0 & 4 \\
\hline Eliminating & Urinates or defecates & 1 & 82 & 14 & 3.8 & 0 & 0 & 2 & - & - & - & - & - & - \\
\hline Exploring & $\begin{array}{l}\text { Looks around or sniffs surrounding while standing } \\
\text { still }\end{array}$ & 0 & 27 & 25 & 12 & 19 & 17 & 30 & 32 & 30 & 22 & 16 & 1.0 & 8 \\
\hline $\begin{array}{l}\text { Any } \\
\text { behaviourc }\end{array}$ & - & - & 29 & 13 & 21 & 21 & 16 & 55 & 55 & 22 & 10 & 11 & 1.9 & 12 \\
\hline
\end{tabular}

${ }^{a}$ Negative impact on animal welfare according to expert opinion: $1=$ mild; $2=$ moderate; or $3=$ severe.

${ }^{\mathrm{b}}$ Maximum number of behaviours recorded for an animal.

"Any of the recorded behaviours, excluding "exploring". 
Table 2

Percentage of animals with different counts of recorded stockperson actions in the driving races $(n=121)$ and stun boxes $(n=283)$ of four Swedish cattle slaughter plants in 2011.

\begin{tabular}{|c|c|c|c|c|c|c|c|c|c|c|c|c|c|c|}
\hline \multirow[t]{2}{*}{ Action } & \multirow[t]{2}{*}{ Description } & \multirow{2}{*}{$\begin{array}{l}\mathrm{AW} \\
\text { rating }^{\mathrm{a}}\end{array}$} & \multicolumn{6}{|c|}{ Count in driving race } & \multicolumn{6}{|c|}{ Count in stun box } \\
\hline & & & 0 & 1 & 2 & $3-5$ & $>5$ & Max. $^{\mathrm{b}}$ & 0 & 1 & 2 & $3-5$ & $>5$ & Max..$^{b}$ \\
\hline Speaking & Speaks or whistles softly and quietly ${ }^{\mathrm{c}}$ & 0 & 49 & 13 & 8.3 & 16 & 14 & 40 & 77 & 10 & 2.8 & 6.4 & 3.2 & 18 \\
\hline Shouting & Speaks or shouts harschly or loudly ${ }^{\mathrm{c}}$ & 2 & 88 & 6.6 & 2.5 & 0.83 & 1.6 & 10 & 98 & 0.71 & 0.71 & 0.71 & 0 & 3 \\
\hline Rattling & Makes noise by shakes rattle or clapping hands ${ }^{c}$ & 1 & 94 & 3.3 & 0.83 & 0.83 & 0.83 & 15 & 100 & 0 & 0 & 0.35 & 0 & 3 \\
\hline Slamming & Makes noise by hitting wall with a tool ${ }^{\mathrm{c}}$ & 1 & 88 & 5.0 & 1.6 & 4.1 & 1.6 & 13 & 98 & 0.71 & 0.35 & 0.35 & 0.71 & 21 \\
\hline Touching rear & Touches the animal behind hip bone with hand & 1 & 77 & 7.4 & 3.3 & 9.1 & 3.3 & 9 & 93 & 2.8 & 1.1 & 2.1 & 1.1 & 7 \\
\hline Touching front & t Touches the animal in front of hip bone with hand & 1 & 92 & 3.3 & 0.83 & 3.3 & 1.6 & 15 & 88 & 8.1 & 1.1 & 2.1 & 0.71 & 49 \\
\hline Slapping rear & Slaps the animal behind hip bone with hand ${ }^{\mathrm{d}}$ & 2 & 90 & 5.8 & 1.6 & 1.6 & 0.83 & 24 & 98 & 0 & 0.35 & 0.71 & 0.35 & 6 \\
\hline Slapping front & Slaps the animal in front of hip bone with hand ${ }^{\mathrm{d}}$ & 2 & 92 & 5.8 & 1.6 & 0 & 0.83 & 6 & 99 & 0 & 0.71 & 0 & 0 & 2 \\
\hline Hitting rear & Touches the animal behind hip bone with tool & 1 & 67 & 5.8 & 7.4 & 11 & 9.1 & 38 & 100 & 0 & 0.35 & 0 & 0 & 2 \\
\hline Hitting front & Touches the animal in front of hip bone with tool & 2 & 89 & 5.0 & 1.6 & 3.3 & 0.83 & 6 & 100 & 0.35 & 0 & 0 & 0 & 1 \\
\hline Beating rear & Beats the animal behind hip bone with tool ${ }^{\mathrm{d}}$ & 3 & 84 & 5.8 & 1.6 & 3.3 & 5.0 & 16 & 100 & 0 & 0 & 0 & 0 & 0 \\
\hline Beating front & Beats the animal in front of hip bone with tool ${ }^{d}$ & 3 & 91 & 3.3 & 3.3 & 0.83 & 1.6 & 11 & 100 & 0 & 0 & 0 & 0 & 0 \\
\hline Booting & Kicks the animal & 3 & 99 & 0.83 & 0 & 0 & 0 & 1 & 100 & 0 & 0 & 0 & 0 & 0 \\
\hline Gate hitting $^{\mathrm{e}}$ & Closes hydraulic tailgate on animal & 2 & 81 & 13 & 5.8 & 0 & 0 & 2 & 46 & 19 & 17 & 16 & 2.5 & 11 \\
\hline Tail twisting & Bends or twists tail & 3 & 98 & 1.6 & 0 & 0 & 0 & 1 & 100 & 0.35 & 0 & 0 & 0 & 1 \\
\hline Prodding & Uses electric goad on animal & 3 & 87 & 3.3 & 5.0 & 3.3 & 1.6 & 13 & 98 & 0.71 & 0.35 & 0.35 & 0.35 & 15 \\
\hline Any action ${ }^{\mathrm{f}}$ & - & - & 37 & 8.3 & 6.6 & 16 & 31 & 112 & 38 & 18 & 17 & 19 & 7.8 & 78 \\
\hline
\end{tabular}

${ }^{a}$ Negative impact on animal welfare according to expert opinion: 1 = mild; 2 = moderate; or 3 = severe.

${ }^{\mathrm{b}}$ Maximum number of stockperson actions recorded for an animal.

${ }^{\mathrm{c}}$ Within 1 animal length from the animal.

${ }^{\mathrm{d}}$ Lifting arm to $>45 \circ$ before slapping or beating.

${ }^{\mathrm{e}}$ Excluding one slaughter plant without a vertical sliding gate $(n=156)$.

fAny of the recorded actions, excluding "speaking". 


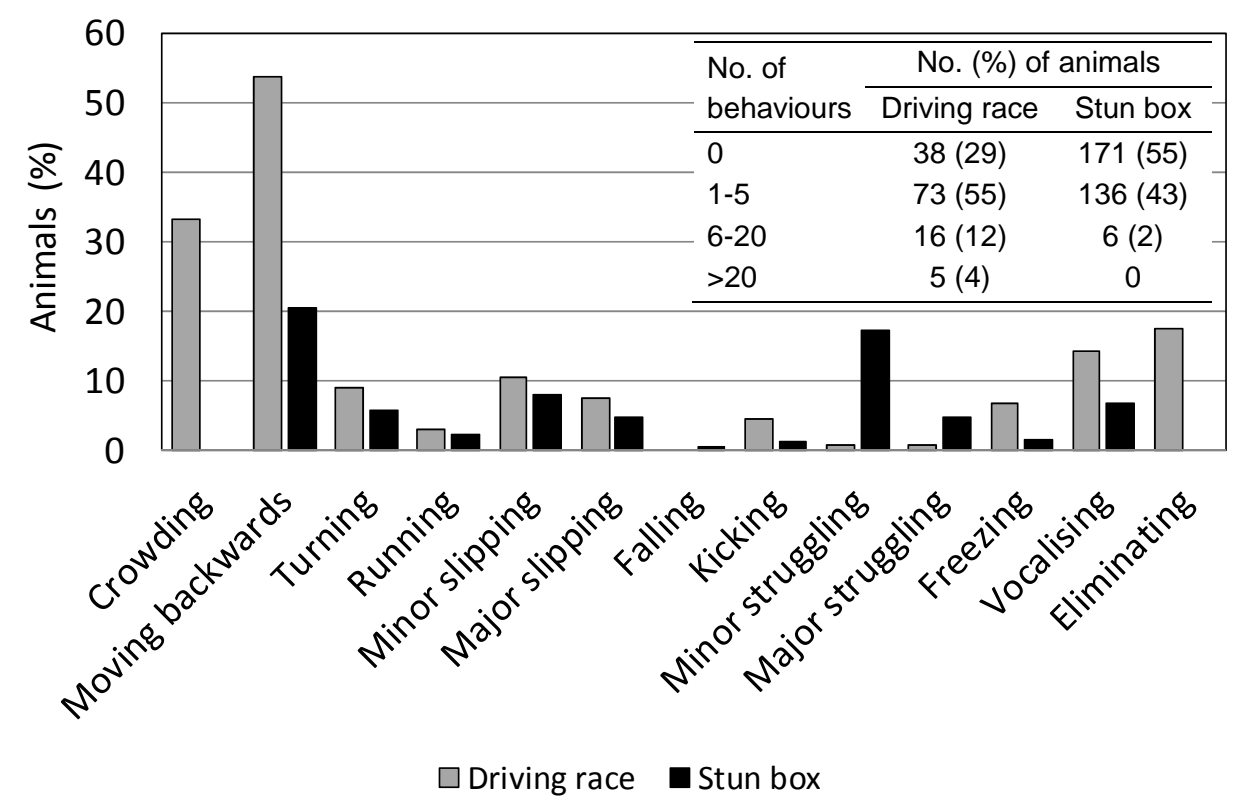

Fig. 2. Percentages of animals displaying different behaviours in the driving races $(n=132)$ and stun boxes $(n=313)$ of four Swedish cattle slaughter plants in 2011; "crowding" and "eliminating" not recorded in stun box; embedded table shows distribution of animals by total number of behaviours displayed (excluding "exploring").

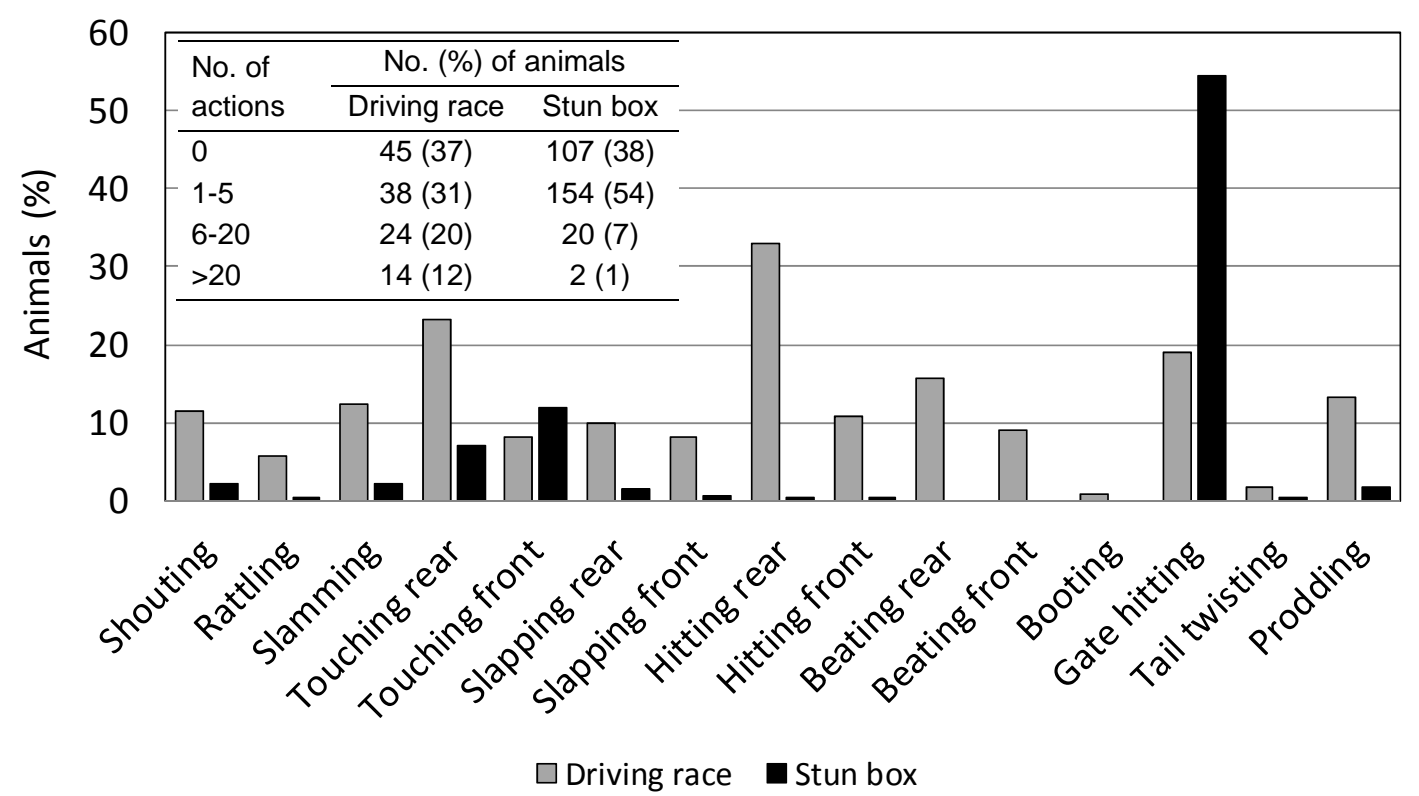

Fig. 3. Percentages of animals exposed to different stockperson actions in the driving races $(n=121)$ and stun boxes $(n=283)$ of four Swedish cattle slaughter plants in 2011; observations of "gate hitting" excluded at one slaughter plant with a divergent stun box design $(n=156)$; embedded table shows distribution of animals by total number of actions received (excluding "speaking").

Descriptive statistics of the counts in different behaviour groups, and of AWBEH and AWACT are shown in Table 3. All correlations with $\rho>0.08$ were positive, as shown in Table 4. Three moderate to strong correlations were found between individual actions ("slapping front" and "slapping rear"; "prodding" and "shouting"; and "prodding" and "beating rear"). The strongest correlations involving AW scores were found between "moving backwards" and AWBEH $(\rho=0.80)$; "crowding" and AWBEH $(\rho=0.59)$; and "beating rear" 
and AWACT $(\rho=0.56)$. The correlation between AWBEH and AWACT was rather weak ( $\rho$ $=0.33$ ). The two most common behaviours were "moving backwards" and "crowding", and the rather weak correlation between them $(\rho=0.37)$ suggests that they were not often displayed together by the same animals. Still, $63 \%$ of the focal animals displayed either both or none of these behaviours. Fig. 4 shows two examples of associations.

Table 3

Descriptive statistics of behaviour counts and animal welfare scores per animal in the driving races $(n=121)$ and stun boxes $(n=283)$ of four Swedish cattle slaughter plants in 2011.

\begin{tabular}{|c|c|c|c|c|c|c|c|c|}
\hline \multirow[b]{2}{*}{ Behaviour group } & \multicolumn{4}{|c|}{ Count/score in driving race } & \multicolumn{4}{|c|}{ Count/score in stun box } \\
\hline & Mean & SD & Median & $\begin{array}{l}\text { Maxi- } \\
\text { mum }\end{array}$ & Mean & SD & Median & $\begin{array}{l}\text { Maxi- } \\
\text { mum }\end{array}$ \\
\hline Backing-turning $^{\mathrm{a}}$ & 1.39 & 2.45 & 1 & 21 & 0.393 & 0.955 & 0 & 8 \\
\hline Slipping-falling ${ }^{\mathrm{b}}$ & 0.265 & 0.837 & 0 & 7 & 0.156 & 0.498 & 0 & 5 \\
\hline Struggling-kicking ${ }^{\mathrm{c}}$ & 0.106 & 0.596 & 0 & 6 & 0.297 & 0.696 & 0 & 4 \\
\hline Any behaviour ${ }^{\mathrm{d}}$ & 3.10 & 6.96 & 1 & 55 & 0.974 & 1.62 & 0 & 12 \\
\hline $\mathrm{AWBEH}^{\mathrm{e}}$ & 7.45 & 14.8 & 4 & 109 & 2.05 & 3.54 & 0 & 25 \\
\hline $\mathrm{AWACT}^{\mathrm{f}}$ & 11.8 & 22.0 & 4 & 157 & 3.23 & 5.08 & 2 & 49 \\
\hline
\end{tabular}

a "Moving backwards" or "turning".

b "Minor slipping", "major slipping" or "falling".

c "Minor struggling", "major struggling" or "kicking".

"Any of the recorded behaviours, excluding "exploring".

eAnimal welfare count per animal derived from behaviours rated by experts.

${ }^{\mathrm{f}}$ Animal welfare count per animal derived from stockperson actions rated by experts.
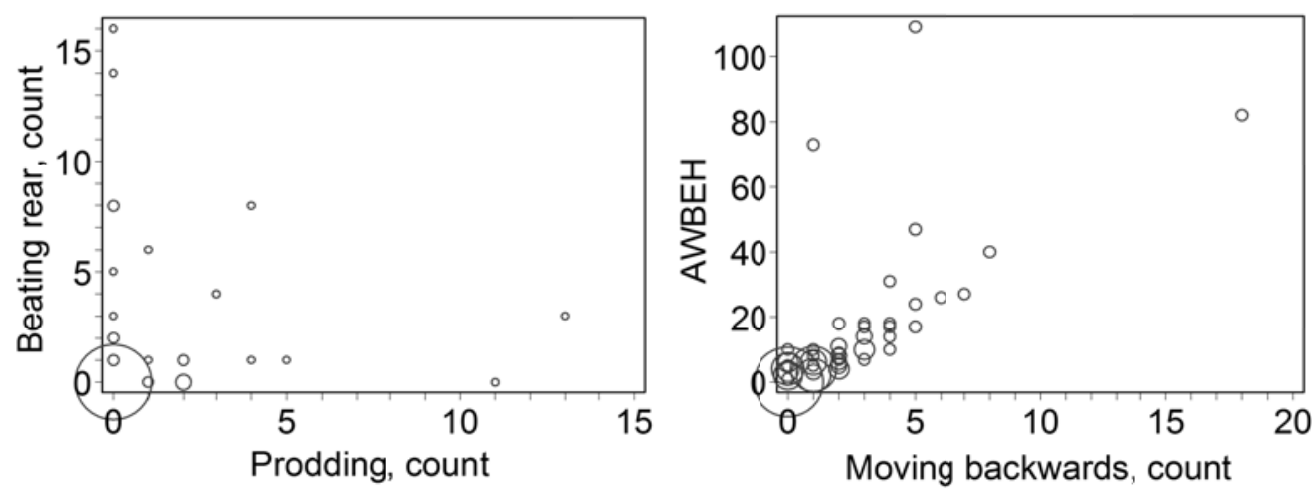

Fig. 4. Two examples of within-animal associations between counts of stockperson actions and animal behaviours: (left) "prodding" and "beating rear"; and (right) "moving backwards" and animal welfare score derived from behaviours rated by experts (AWBEH), in the driving races of four Swedish cattle slaughter plants in $2011(n=121)$; the area of each circle is proportionate to the number of observations.

According to the negative binomial models, slaughter plant had a significant effect on "backing-turning" $(P<0.0001)$, "slipping-falling $(P=0.0006)$ and "any behaviour" $(P<$ $0.0001)$, but not on "struggling-kicking" (full models not presented). Predicted counts $(95 \%$ confidence intervals) for the models' base level (dairy cows at plant 1$)$ were $1.48(0.52-2.4)$ "backing-turning"; $0.11(-0.08-0.30)$ "slipping-falling"; $0.13(-0.08-0.33)$ "strugglingkicking"; and 4.0 (1.7-6.3) "any behaviour". Adult bulls had a 2.2 times higher risk of displaying "backing-turning" than had dairy cows $(P=0.014)$. No other significant effects of animal category were found. Due to missing data for some animals, between 112 and 121 observations could be used in the models. The dispersion parameter alpha indicated a 
Table 4

Rank correlations between action/behaviour counts and animal welfare scores per animal in the driving races (lower left) and stun boxes (upper right) of four Swedish cattle slaughter plants in 2011.

\begin{tabular}{|c|c|c|c|c|c|c|c|c|c|c|c|c|c|c|c|c|c|c|c|c|}
\hline & \multicolumn{9}{|c|}{$\begin{array}{c}\text { Stockperson actions } \\
(n=121 \text { in driving race; } 283 \text { in stun box })\end{array}$} & \multicolumn{11}{|c|}{$\begin{array}{c}\text { Animal behaviours } \\
(n=132 \text { in driving race; } 313 \text { in stun box })\end{array}$} \\
\hline & Shouting & $\begin{array}{l}\text { Slapping } \\
\text { rear }\end{array}$ & $\begin{array}{l}\text { Slapping } \\
\text { front }\end{array}$ & $\begin{array}{l}\text { Hitting } \\
\text { front }\end{array}$ & $\begin{array}{l}\text { Beating } \\
\text { rear }\end{array}$ & $\begin{array}{l}\text { Beat- } \\
\text { ing } \\
\text { front }\end{array}$ & $\begin{array}{l}\text { Gate } \\
\text { hitting }\end{array}$ & Prodding & $\mathrm{AWACT}^{\mathrm{a}}$ & $\begin{array}{l}\text { Crow- } \\
\text { ding }\end{array}$ & $\begin{array}{l}\text { Moving } \\
\text { back- } \\
\text { wards }\end{array}$ & Turning & $\begin{array}{l}\text { Run- } \\
\text { ning }\end{array}$ & $\begin{array}{l}\text { - Major } \\
\text { slip- } \\
\text { ping }\end{array}$ & $\begin{array}{l}\text { Kick- } \\
\text { ing }\end{array}$ & $\begin{array}{l}\text { Minor } \\
\text { strug- } \\
\text { gling }\end{array}$ & $\begin{array}{l}\text { Major } \\
\text { strug- } \\
\text { gling }\end{array}$ & $\begin{array}{l}\text { Freez- } \\
\text { ing }\end{array}$ & $\begin{array}{l}\text { Voca- } \\
\text { lising }\end{array}$ & $\mathrm{AWBEH}^{\mathrm{b}}$ \\
\hline Shouting & - & $\begin{array}{l}-0.02 \\
\end{array}$ & - & - & - & - & $0.17^{* *}$ & $\begin{array}{l}-0.02 \\
\end{array}$ & $0.21^{* * * *}$ & - & 0.05 & 0.06 & -0.02 & $\begin{array}{|ll|}2 & 0.08 \\
\end{array}$ & - & 0.12 & 0.08 & $\begin{array}{l}-0.02 \\
\end{array}$ & -0.04 & 0.07 \\
\hline $\begin{array}{l}\text { Slapping } \\
\text { rear }\end{array}$ & 0.06 & - & - & - & - & - & -0.05 & $0.21^{* * *}$ & $0.21^{* * *}$ & - & 0.02 & -0.03 & -0.02 & $2-0.03$ & - & -0.06 & -0.03 & -0.01 & -0.03 & -0.04 \\
\hline $\begin{array}{l}\text { Slapping } \\
\text { front }\end{array}$ & 0.07 & $0.40^{* * * *}$ & - & - & - & - & - & - & - & - & - & - & - & - & - & - & - & - & - & - \\
\hline $\begin{array}{l}\text { Hitting } \\
\text { front }\end{array}$ & 0.16 & 0.17 & $0.27^{* *}$ & - & - & - & - & - & - & - & - & - & - & - & - & - & - & - & - & - \\
\hline $\begin{array}{l}\text { Beating } \\
\text { rear }\end{array}$ & $0.21^{*}$ & 0.08 & $0.20^{*}$ & 0.16 & - & - & - & - & - & - & - & - & - & - & - & - & - & - & - & - \\
\hline $\begin{array}{l}\text { Beating } \\
\text { front }\end{array}$ & 0.06 & 0.17 & $0.29^{* * *}$ & $0.24^{* *}$ & 0.09 & - & - & - & - & - & - & - & - & - & - & - & - & - & - & - \\
\hline $\begin{array}{l}\text { Gate } \\
\text { hitting }\end{array}$ & $0.21^{*}$ & 0.12 & -0.005 & 0.17 & -0.03 & -0.02 & - & 0.01 & $0.93^{* * * *}$ & - & $0.28^{* * * *}$ & 0.09 & -0.04 & $\begin{array}{ll}4 & 0.04\end{array}$ & - & 0.09 & -0.002 & $-0.12^{*}$ & 0.11 & $0.25^{* * * *}$ \\
\hline Prodding & $0.49^{* * * *}$ & $0.37^{* * * *}$ & $0.21^{*}$ & $0.35^{* * * *}$ & $0.42^{* * * * *}$ & $0.21^{*}$ & 0.11 & - & $0.21^{* * *}$ & - & -0.07 & -0.03 & -0.02 & $2-0.03$ & - & 0.005 & -0.03 & -0.02 & -0.04 & -0.08 \\
\hline AWACT ${ }^{\mathrm{a}}$ & $0.34^{* * * *}$ & $0.34^{* * * *}$ & $0.32^{* * * *}$ & $0.43^{* * * *}$ & $0.56^{* * * *}$ & $0.32^{* * *}$ & $0.27^{* *}$ & $0.53^{* * * *}$ & - & - & $0.26^{* * * *}$ & 0.07 & -0.05 & $\begin{array}{ll}5 & 0.02\end{array}$ & - & 0.08 & -0.01 & $-0.12^{*}$ & 0.09 & $0.22^{* * *}$ \\
\hline Crowding & 0.03 & 0.02 & -0.06 & $0.20 *$ & 0.08 & 0.13 & $0.23^{*}$ & -0.05 & 0.17 & - & - & - & - & - & - & - & - & - & - & - \\
\hline $\begin{array}{l}\text { Moving } \\
\text { backwards }\end{array}$ & $0.23^{*}$ & 0.05 & 0.06 & 0.13 & $0.21^{*}$ & 0.08 & 0.15 & $0.22^{*}$ & $0.31^{* * *}$ & $0.37^{* * * *}$ & - & $0.28^{* * * *}$ & 0.03 & $0.18^{* *}$ & - & 0.06 & 0.05 & $0.20^{* * *}$ & 0.001 & $0.61^{* * * *}$ \\
\hline Turning & $0.32^{* * *}$ & 0.09 & -0.004 & 0.16 & 0.16 & 0.07 & -0.03 & $0.29^{* *}$ & $0.19^{*}$ & 0.16 & $0.22^{*}$ & - & 0.05 & 0.01 & - & $0.33^{* * * *}$ & $0.21^{* * *}$ & -0.03 & $0.26^{* * *}$ & $0.40^{* * * *}$ \\
\hline Running & - & - & - & - & - & - & - & - & - & - & - & - & - & 0.06 & - & 0.10 & $0.16^{* *}$ & -0.02 & 0.04 & $0.19^{* * *}$ \\
\hline $\begin{array}{l}\text { Major } \\
\text { slipping }\end{array}$ & $0.26^{* *}$ & -0.006 & 0.02 & $0.18^{*}$ & 0.14 & 0.01 & 0.14 & 0.06 & 0.08 & 0.16 & 0.14 & $0.20^{*}$ & - & - & - & 0.01 & $0.17^{* *}$ & 0.09 & -0.06 & $0.32^{* * * *}$ \\
\hline Kicking & $0.27^{* *}$ & 0.05 & -0.07 & $0.31^{* * *}$ & 0.12 & -0.07 & -0.02 & $0.39^{* * * *}$ & $0.25^{* *}$ & 0.11 & $0.30^{* * *}$ & $0.32^{* * * *}$ & - & 0.07 & - & - & - & - & - & - \\
\hline $\begin{array}{l}\text { Minor } \\
\text { struggling }\end{array}$ & - & - & - & - & - & - & - & - & - & - & - & - & - & - & - & - & $0.22^{* * * *}$ & -0.06 & $0.18^{* *}$ & $0.55^{* * * *}$ \\
\hline $\begin{array}{l}\text { Major } \\
\text { struggling }\end{array}$ & - & - & - & - & - & - & - & - & - & - & - & - & - & - & - & - & - & -0.03 & -0.06 & $0.36^{* * * *}$ \\
\hline Freezing & 0.10 & $0.22^{*}$ & 0.15 & $0.23^{*}$ & $0.32^{* * *}$ & -0.09 & 0.02 & $0.35^{* * * *}$ & $0.34^{* * * *}$ & 0.008 & $0.19^{*}$ & 0.02 & - & 0.03 & $0.24^{* *}$ & - & - & - & -0.03 & $0.17^{* *}$ \\
\hline Vocalising & $0.20^{*}$ & -0.06 & -0.03 & 0.07 & 0.08 & -0.05 & -0.10 & 0.03 & -0.06 & -0.003 & $0.25^{* * *}$ & 0.02 & - & 0.12 & 0.12 & - & - & 0.14 & - & $0.35^{* * * *}$ \\
\hline $\mathrm{AWBEH}^{\mathrm{b}}$ & $0.27^{* *}$ & 0.07 & 0.11 & $0.24^{* *}$ & $0.22^{*}$ & 0.13 & $0.19^{*}$ & $0.24^{* *}$ & $0.33^{* * *}$ & $0.59^{* * * *}$ & $0.80^{* * * *}$ & $0.29^{* * *}$ & - & $0.32^{* * *}$ & $0.28^{* *}$ & - & - & $0.25^{* *}$ & $0.42^{* * * *}$ & - \\
\hline
\end{tabular}

${ }^{\mathrm{A}}$ A nimal welfare count per animal derived from stockperson actions rated by experts.

${ }^{\mathrm{b}}$ Animal welfare count per animal derived from behaviours rated by experts.

$* P \leq 0.05 ; * * P \leq 0.01$; *** $P \leq 0.001 ; * * * * P \leq 0.0001$. 
significant deviation from the Poisson distribution in all models, supporting the choice of a negative binomial distribution.

The models of AWBEH and AWACT are presented in Tables 5 and 6, and predicted counts are shown in Fig. 5. Plant had a significant effect on both AWBEH and AWACT $(P<$ 0.0001 ), while animal category had no significant effect.

Table 5

Negative binomial models of animal welfare score derived from behaviours rated by experts, in the driving races $(n=121)$ and stun boxes ( $n=279$, of which 150 zeros) of four Swedish cattle slaughter plants in 2011, using $\ln$ (observation time) as offset.

\begin{tabular}{|c|c|c|c|c|c|c|c|}
\hline \multirow[b]{2}{*}{ Predictor } & \multirow[b]{2}{*}{ Level } & \multicolumn{3}{|c|}{ Driving race } & \multicolumn{3}{|c|}{ Stun box ${ }^{\mathrm{a}}$} \\
\hline & & Coef. & SE & $P$ & Coef. & SE & $P$ \\
\hline \multicolumn{2}{|l|}{ Intercept } & -3.57 & 0.248 & $<0.0001$ & -3.26 & 0.169 & $<0.0001$ \\
\hline \multirow[t]{4}{*}{ Plant } & 1 & (base) & & $<0.0001^{\mathrm{b}}$ & (base) & & $<0.0001^{b}$ \\
\hline & 2 & 0.672 & 0.207 & 0.001 & 1.15 & 0.221 & $<0.0001$ \\
\hline & 3 & -1.80 & 0.350 & $<0.0001$ & -2.01 & 0.488 & $<0.0001$ \\
\hline & 4 & -1.66 & 0.292 & $<0.0001$ & -0.309 & 0.230 & 0.18 \\
\hline \multirow{4}{*}{$\begin{array}{l}\text { Animal } \\
\text { category }\end{array}$} & Dairy cows & (base) & & $0.097^{\mathrm{b}}$ & (base) & & $0.29^{\mathrm{b}}$ \\
\hline & Beef cows & -0.121 & 0.319 & 0.70 & -0.452 & 0.624 & 0.47 \\
\hline & Adult bulls & 0.454 & 0.234 & 0.052 & 0.289 & 0.198 & 0.14 \\
\hline & Heifers/bullocks & 0.102 & 0.264 & 0.70 & 0.322 & 0.252 & 0.20 \\
\hline \multirow{7}{*}{$\begin{array}{l}\text { Alpha } \\
\text { Inflate par } \\
\text { Intercept } \\
\text { Category }\end{array}$} & & -3.57 & 0.248 & $<0.0001^{\mathrm{c}}$ & 0.504 & 0.140 & $<0.05^{\mathrm{c}}$ \\
\hline & of model: & & & & & & $0.0026^{\mathrm{d}}$ \\
\hline & & - & & & -0.624 & 0.364 & 0.087 \\
\hline & Dairy cows & - & & & (base) & & \\
\hline & Beef cows & - & & & 0.872 & 0.869 & 0.32 \\
\hline & Adult bulls & - & & & -1.15 & 0.630 & 0.068 \\
\hline & Heifers/bullocks & - & & & 0.862 & 0.490 & 0.079 \\
\hline
\end{tabular}

${ }^{\mathrm{a}}$ Zero-inflated negative binomial model.

${ }^{\mathrm{b}} P$ value of joint Chi-square test of effect.

${ }^{\mathrm{c}} P$ value of likelihood-ratio test of alpha $=0$.

${ }^{\mathrm{d}} P$ value of Vuong test of zero-inflated vs. standard negative binomial model.

\subsection{Stun box}

In the stun box, 313 animals were observed (128, 80, 78 and 27 animals at the four slaughter plants). The total observation times in the stun box at the four plants were 167, 54, 42 and 20 min, respectively, resulting in mean (min.-median-max.) observation times of 1.3 (0.2-1.1-6.4), $0.9(0.4-0.68-2.5), 0.8(0.1-0.63-4.0)$ and $0.7(0.02-0.33-4.3) \mathrm{min} / \mathrm{animal}$.

The behaviours observed in the highest number of animals in the stun box were "moving backwards" and "minor struggle" (Table 1). The maximum behaviour count was 12, displayed by one animal, and 171 animals displayed none of the recorded behaviours (excluding "exploring").

Eight stockpersons were observed stunning 1 to 72 focal animals each. Some actions were mainly displayed by one or two stockpersons at one plant. The action displayed towards the highest number of animals (54\%) was "gate hitting" (Table 2), which was used to prevent a second animal from entering the stun box or make it back out. Notably, this was generally done cautiously and with a low force. Either "tail twisting" or repeated use of an electric goad was observed in three animals in the stun box. The maximum action count was 78 , received by 1 animal, and 107 animals received none of the recorded actions (excluding "speaking"). No "beating rear", "beating front" or "booting" was seen in the stun box. 


\section{Table 6}

Negative binomial models of animal welfare score derived from stockperson actions rated by experts, in the driving races $(n=112)$ and stun boxes $(n=270)$ of four Swedish cattle slaughter plants in 2011, using $\ln$ (observation time) as offset.

\begin{tabular}{llccccccc}
\hline & & \multicolumn{3}{c}{ Driving race } & & \multicolumn{3}{c}{ Stun box } \\
\cline { 3 - 5 } Predictor & Level & Coef. & SE & $P$ & & Coef. & SE & $P$ \\
\hline Intercept & & -2.99 & 0.368 & $<0.0001$ & & -2.60 & 0.146 & $<0.0001$ \\
Plant & 1 & $($ base $)$ & & $<0.0001^{\mathrm{a}}$ & & $($ base $)$ & & $<0.0001^{\mathrm{a}}$ \\
& 2 & 0.693 & 0.346 & 0.045 & & -1.71 & 0.290 & $<0.0001$ \\
& 3 & -1.68 & 0.538 & 0.002 & & -1.63 & 0.430 & $<0.0001$ \\
& 4 & -0.958 & 0.481 & 0.046 & & 0.483 & 0.159 & 0.002 \\
Animal & Dairy cows & $($ base $)$ & & $0.75^{\mathrm{a}}$ & & $($ base $)$ & & $0.28^{\mathrm{a}}$ \\
category & & & & & & & \\
& Beef cows & 0.357 & 0.485 & 0.46 & & 0.221 & 0.447 & 0.62 \\
& Adult bulls & -0.018 & 0.377 & 0.96 & & 0.0352 & 0.168 & 0.834 \\
& Heifers/bullocks & 0.294 & 0.412 & 0.47 & & -0.317 & 0.206 & 0.12 \\
Alpha & & 1.86 & 0.278 & $<0.0001^{\mathrm{b}}$ & & 0.887 & 0.119 & $<0.0001^{\mathrm{b}}$ \\
\hline
\end{tabular}

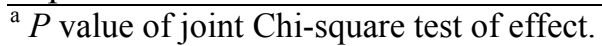

${ }^{\mathrm{b}} P$ value of likelihood-ratio test of alpha $=0$.
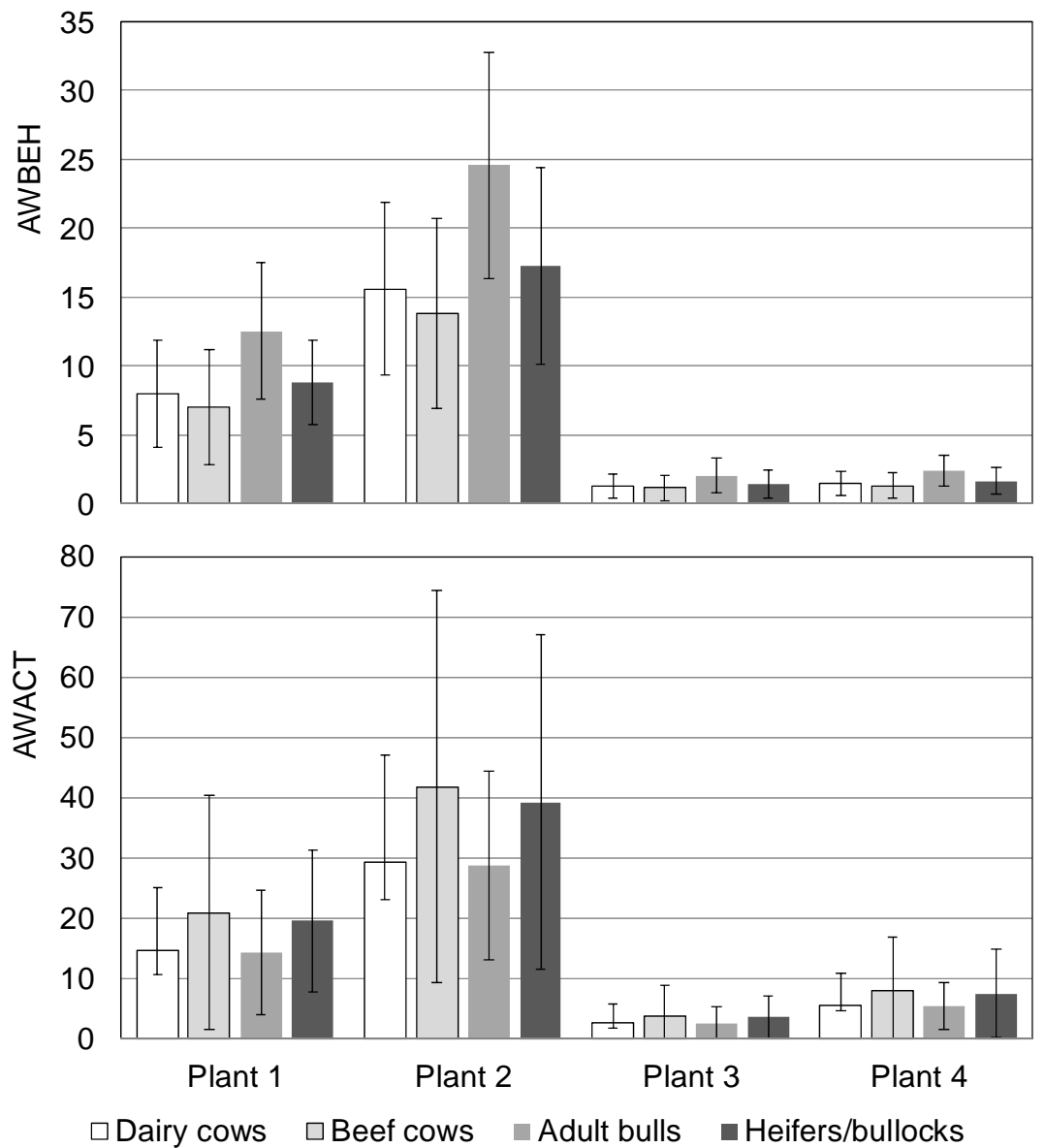

Fig. 5. Predicted animal welfare scores derived from behaviours (AWBEH) and stockperson actions (AWACT) rated by experts, in four different animal categories in the driving races of four different Swedish cattle slaughter plants in $2011(n=121)$, according to negative binomial models; error bars represent $95 \%$ confidence intervals. 
Sixty-eight animals (24\%) displayed no recorded behaviours at all and had no recorded stockperson actions directed towards them, 79 animals (28\%) showing no recorded behaviours received 1 to 23 stockperson actions, and 39 animals (14\%) had no stockperson actions recorded but displayed one to seven recorded behaviours (excluding "exploring" and "speaking"). Combining the percentages from driving races and stun boxes (assuming independence despite the fact that different animals were observed in the two process steps) showed that $36 \%$ of the cattle were processed without displaying/receiving any of the recorded behaviours/actions indicating poor AW (excluding "exploring" and "speaking") while being observed, and that $66 \%$ did not display/receive any of the behaviours/actions associated with the highest negative AW rating (3). Consequently, at least $64 \%$ showed one or more of the recorded behaviours/actions at the abattoir, and at least 34\% showed behaviours/actions indicating severely compromised AW. The strongest rank correlation between individual behaviours or actions was found between "turning" and "minor struggling" $(\rho=0.33 ; P<0.0001$; Table 4$)$. The strongest correlation involving AW scores was found between "moving backwards" and AWBEH $(\rho=0.61)$. As in the driving race, the correlation between AWBEH and AWACT was rather weak $(\rho=0.22)$.

According to the negative binomial models, slaughter plant had a significant effect on "backing-turning" $(P=0.0002)$, "slipping-falling" $(P=0.0058)$, "strugglingkicking" $(P=$ $0.0027)$ and "any behaviour" $(P<0.0001)$ (full models not presented). Predicted counts $(95 \%$ confidence intervals) for the models' base level (dairy cows at plant 1$)$ were $0.36(0.18-0.54)$ "backing-turning"; 0.25 (0.06-0.44) "slipping-falling"; 0.17 (0.06-0.28) "struggling-kicking"; and $0.83(0.55-1.1)$ "any behaviour". Adult bulls had a 2.0 times higher risk of displaying "backing-turning" $(P=0.016)$, a 2.5 times higher risk of "struggling-kicking" $(P=0.016)$, and a 1.6 times higher risk of "any behaviour" $(P=0.029)$ than had dairy cows.

Heifers/bullocks had a 3.2 times lower risk of displaying "slipping-falling" than dairy cows $(P$ $=0.050)$. There were no other significant effects of animal category. Due to missing data for some animals, between 270 and 279 observations could be used. As shown by Tables 5 and 6 , plant had a significant effect on AWBEH and AWACT $(P<0.0001)$, while animal category had no such effect. The model of AWBEH predicted the probability of being in the "certain zero" group to be 0.65 for dairy cows, 0.44 for beef cows, 0.85 for adult bulls and 0.44 for heifers/bullocks, indicating the proportions of all animals slaughtered that are processed without any of the recorded signs of poor AW while they are in the stun box. Predicted AWBEH and AWACT counts are shown in Fig. 6.

The percentage of animals shot more than once was $0 \%, 4 \%, 4 \%$ and $12 \%$ at the four plants, or $7 \%$ in dairy cows, $0 \%$ in beef cows, $10 \%$ in adult bulls and $4 \%$ in heifers/bullocks. One adult bull and one heifer/bullock were shot three times each, and one dairy cow was shot four times. At the plant where one $(n=65)$, two $(n=50)$ or three $(n=12)$ persons were working the animals in the stun box, the percentage of animals displaying "major struggling" was $1.5,8.0$ and $8.3 \%$, respectively; the mean observation time was $1.1,1.4$ and 2.2 min per animal, respectively; and the percentage of animals re-shot was 4.6, 20 and 25\%, respectively. All the animals shot more than twice were handled in the stun box by more than one stockperson.

\section{Discussion}

\subsection{Stockperson actions and animal behaviours}

This observational study showed that at least $64 \%$ of the cattle slaughtered at four Swedish abattoirs displayed/ received one or more of the recorded behaviours or stockperson actions indicative of impaired AW. At least 34\% displayed/received behaviours/actions 

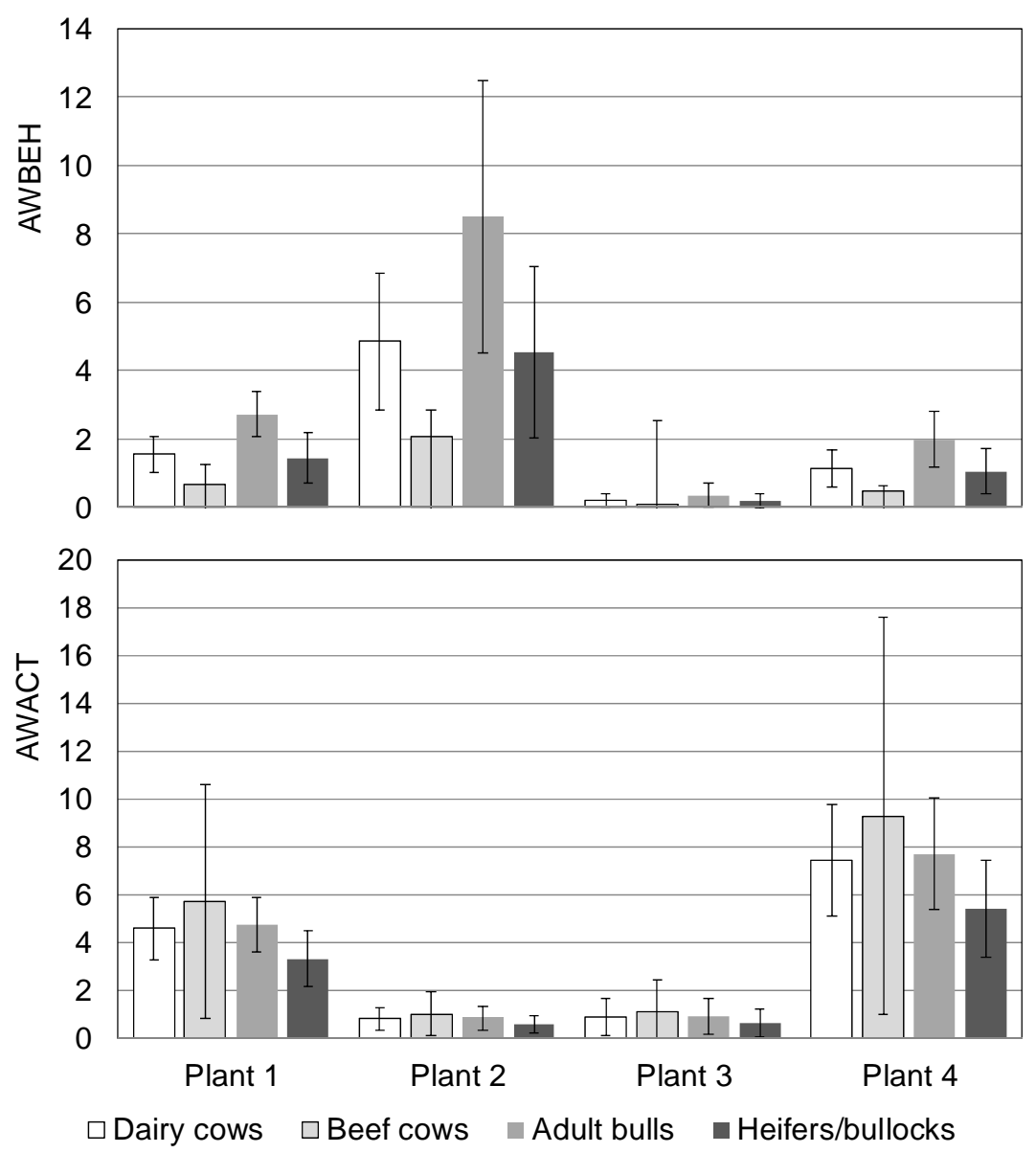

Fig. 6. Predicted animal welfare scores derived from behaviours (AWBEH) and stockperson actions (AWACT) rated by experts, in four different animal categories in the stun boxes of four different Swedish cattle slaughter plants in $2011(n=279)$, according to negative binomial models; error bars represent $95 \%$ confidence intervals.

associated with severely compromised AW. The study also showed that at least $37 \%$ of the cattle received more than five stockperson action events during pre-slaughter handling at the abattoir and at least $18 \%$ displayed more than five behavioural events. At least $20 \%$ of the cattle displayed vocalisations; Grandin (2012) judged a percentage $>3$ to be unacceptable and $>20$ to indicate a serious problem. We observed $1 \%$ of the animals falling, which Grandin (2012) regarded an acceptable level. Directly inappropriate actions were relatively rare; either "tail twisting", repeated use of an electric goad or "booting" was observed in less than $10 \%$ of the animals in the driving race and less than $1 \%$ in the stun box.

Electric goads are very stressful for cattle (Warner et al., 2007). According to Grandin (2010), the percentage of animals moved with an electric goad is one of five measures recorded by private industry and some governments when auditing animal welfare at slaughter plants. Grandin (2012) reported that all 34 USA and Canadian beef plants audited by two major restaurant companies used electric goads in $25 \%$ or less of the animals, which was judged as an acceptable practice. This study shows that at least $15 \%$ of the cattle were moved with an electric goad; the action was observed in $13 \%$ of the focal animals in the driving race and $2 \%$ in the stun box. In the driving race, electric goads were used mainly by three persons at two of the plants. Only at one slaughter plant were they used in the stun box, and almost solely by one stockperson. The observed variation in electric goad usage in the 
stun box can be explained partly by the existence of a horizontal forcing gate at one plant, considerably facilitating the driving of animals into the box. Two animals in the driving race and one in the stun box were observed receiving 10 to 15 electric prods each, which we suggest is unacceptable.

"Booting" was only observed once (in the race), while "slapping rear/front" and "beating rear/front" was observed repeatedly; three animals each received 16 to 24 such actions. Hitting with or without a tool is a common way to drive animals at slaughter plants, although current Swedish legislation prohibits it, just as it prohibits tail twisting and excessive use of an electric goad. "Slapping front" or "beating front" may be an attempt to resolve crowding, to stop an animal from moving forward, or to drive it forward without regard to the point of balance (Kilgour and Dalton, 1984). In turn, crowding can result from a faulty driving race design. If many animals move backwards, as observed in this study, or refuse to move forward it might be because they are distracted by e.g. shadows, conspecifics or persons entering the flight zone in front of the point of balance (Grandin, 2007). One animal received 38 "hitting rear" and two animals received 15 and 49 "touching front", representing fast sequences of repeated mild actions. It is unclear whether or not the stockpersons carried out these actions deliberately, attempting to move the animals, or if they acted habitually and even unintentionally. Despite the sometimes high frequencies of these actions, we regarded them to have a mild negative impact on AW (or, in the case of "hitting front", a moderate negative impact). However, we have not found any literature to support this interpretation; more research is needed to reveal possible effects on the animals from being loosely touched or hit frequently at pre-slaughter handling, and the relevance for AW.

The most common stockperson action in the stun box was "gate hitting". If a second animal was trying to enter the stun box, the vertical tailgate at the entrance to the stun box was sometimes closed onto the back of the animal to make it back out, as described by Bourguet et al. (2011). However, the associated AW risks probably depend on the handling of the gate. Grandin (1998b) observed vocalisations in response to excessive pressure from hydraulic tailgates. In this study, we found that the operators generally used the gates cautiously and with a low force.

A penetrating captive bolt gun was used in three of the studied plants. This is the most common stunning method for cattle in industrial slaughter (Food Chain Evaluation Consortium, 2007; Terlouw et al., 2008). Re-shooting was carried out on 7.1\% of the animals and most commonly in adult bulls, which is consistent with Atkinson et al. (2013) and Gregory et al. (2007), respectively. In other countries, studies of cattle shot with penetrating bolt weapons have reported $9 \%$ to $32 \%$ of the animals being incorrectly stunned (Gregory et al., 2007; Gouveia et al., 2009; Von Wenzlawowicz et al., 2012). Inadequate bolt stunning probably has a major negative impact on AW and should therefore not be accepted in commercial slaughter (Grandin, 1998a; Gregory and Shaw, 2000), but a discussion of such effects is beyond the scope of this paper.

Ideally, the abattoir design should facilitate animal movements to stunning. It should also encourage the stockpersons to optimal actions towards the animals, making it possible to use the animal's flight zones for driving. Solid walls are beneficial because they keep the animals from being distracted by people, conspecifics and other stimuli (Grandin, 1997). Grandin (2007) also observed that some wild cattle seemed more agitated in a race with open sides compared to a race with solid walls, which could be an indication that solid walls make driving easier. However, very high solid walls prevent the stockpersons from making use of the animals' flight zones for moving them. In such instances, a platform next to the race may facilitate driving.

AW in connection with driving and stunning at the abattoir is also influenced by individual characteristics like breed, sex, age and earlier experience. For instance, Lensink et 
al. $(2000 \mathrm{a}, \mathrm{b})$ showed that calves that have received positive and more frequent contacts from their stockbreeder are easier to handle and less stressed during loading. Similarly, Bourguet et al. (2010) found emotional reactivity of cows during rearing to predict stress status at slaughter. None of these individual factors were possible to record in this study. However, adult bulls displayed significantly more "moving backwards" and "turning" than dairy cows, as well as more "struggling-kicking" than dairy cows in the stun box, and heifers/bullocks performed less "strugglingkicking" than dairy cows in the stun box. Corresponding differences between animal categories were not seen for stockperson actions, suggesting that the identified differences regarding behaviours did not result from the way the animals were handled. These findings accord with earlier studies on slaughter procedures (Jarvis et al., 1995; Strappini et al., 2009) that males are more demanding and difficult to handle, and indicate that bulls experience a lower level of AW at slaughter than other animal categories. To our knowledge, similar results have not been published previously. The model effects (coefficient estimates) of slaughter plant were similar for AWBEH and AWACT in the driving race, but radically different in the stun box, i.e. the expected AW scores for actions and behaviours in the driving race at a particular plant were either both high or both low, while such a relationship was not found in the stun box. This might imply that actions and behaviours to a certain degree were performed in response to each other in the race, but less so in the stun box. A more detailed analysis of the data may reveal such sequential patterns of actions and behaviours.

One stockperson displayed a large number of actions, which was especially evident in the driving race, where he performed most of the recorded actions. Very high solid walls of the driving race at this particular slaughter plant is a possible explanation. High action counts for some stockpersons may also be explained by problematic personal attitudes towards slaughter animals, a lack of knowledge about animal behaviour, and poor animal handling skills.

Attitudes of abattoir stockpersons towards animals influence how they treat cattle at slaughter, as shown by Coleman et al. $(2003,2012)$, who found that the pressures imposed on abattoir stockpersons by a perceived lack of control over their actions, perceived time constraints, a perceived effect of poor facilities and inappropriate beliefs about arousing livestock were all associated with frequent use of forceful handling actions. The degree of knowledge and skills can be expected to vary considerably between stockpersons, depending on e.g. time of experience and education. Before Council Regulation (EC) No. 1099/2009 (on the protection of animals at the time of killing) came into force on 1 Jan. 2013, requiring formal education of all abattoir stockpersons, the amount of theoretical and practical training was possibly unsatisfactory in some persons, including stockpersons in the present study. The results of the studies by Coleman et al. $(2003,2012)$ indicate that there may be an opportunity to improve stockperson actions and consequently reduce stress in cattle at abattoirs by targeting attitudes with appropriate educational and training material. Moreover, the management of an abattoir probably plays an important normative role for the staff, as suggested by Grandin (2013), who stated that "Maintaining high standards of animal welfare requires management commitment to welfare". The importance of good management to secure acceptable AW was also indicated by an interview study of 14 stockpersons at six Swedish cattle and pig slaughter plants (Wickman, 2013).

We found only three moderate to strong correlations between animal behaviours or stockperson actions in the driving race, of 105 tested associations. All these correlations were between actions, i.e. not involving behaviours. None of the 74 tested correlations between individual behaviours/actions in the stun box were moderate to strong. The lack of important correlations between one behaviour and one action might suggest that slaughter plant design or events not aimed directly at the animals, such as noise from distant sources or persons passing close to the driveway, are more important for AW than stockperson-animal 
interactions. However, more research is needed to confirm this. Directed acoustic signals ("shouting", "rattling" and "slamming"), were also likely to have affected more than one animal, if there were others nearby (Waynert et al., 1999). Focal animals may have responded behaviourally to such actions although they were directed to other animals, which would have contributed to weak associations between these actions and the animal behaviours displayed in response to them. However, "shouting" was the only acoustic signal included in the tested correlations.

\subsection{Methodological considerations}

The studied slaughter plants were to a great extent selected based on availability and convenience; they basically constituted an accidental sample of facilities that were willing to participate in the study. The large variation between the studied abattoirs in design and staff skills, as well as occurrence of stockperson actions and animal behaviours, implies that the study might not give a complete picture of the conditions and resulting risks of high behaviour counts at all Swedish abattoirs. Nevertheless, pre-formulated abattoir inclusion critera were fulfilled, and based on the authors' extensive knowledge about Swedish cattle slaughter, the studied plants can be regarded as fairly representative of all Swedish large-scale cattle abattoirs, with a good geographical spread. Within each of the four study plants, the observed animals can be regarded as a random sample of all cattle processed, which limits the risk of selection bias.

The recorded animal behaviours and stockperson actions were selected based on earlier research (Welfare Quality, 2009) and on extensive experience of slaughter in Sweden and elsewhere. Hemsworth et al. (2011) observed behaviours with similar labels in a study of human-animal interaction at slaughter plants. In the current study, experienced experts in the field rated behaviours and actions for AW, which secured a relatively complete and reliable assessment of the AW status in the animals observed. In a study to develop guidelines for AW risk assessment of stunning and killing of various species, Algers et al. (2009) used a fivelevel scale from 0 ("negligible") to 4 ("critical", fatal) for intensity of adverse AW effects, and scored the effects on beef cattle of hitting, shouting and inadequate handling in the passageway as being intensity 2 ("some pain, malaise, frustration, fear or anxiety; stress reaction; some change in motor behaviour, occasional vocalisation may occur"). In the race into the stunning area, the same authors scored hitting, shouting, untrained or unmotivated handlers, and the use of prods, electric goads or sticks as resulting in effects of intensity 3 ("strong stress reaction; dramatic change in motor behaviour, vocalisation may occur"). Our AW ratings accord with these scorings. Nevertheless it can be argued that some aspects of impaired AW were overlooked, such as mild distress, pain and other mental states which are not reflected in behaviour in such a way that they can be assessed reliably.

The importance of positive emotions in animals, and methods to assess positive AW, are attracting increasing scientific attention, as reviewed by Yeates and Main (2008).

Wemelsfelder and Lawrence (2001) introduced an on-farm AW monitoring tool, allowing for reliable recordings of both negative and positive emotional states, which would be possible to apply also in abattoirs. However, in the slaughter situation cattle are exposed to a number of stressful factors which are likely to overshadow any positive stimuli and dominate the animals' perception of their environment. Consequently, we focussed on behaviours and stockperson actions related to impaired AW. We do not consider soft and quiet speech or whistling detrimental to AW. Instead, like Hemsworth et al. (2011) we suggest that such actions can have a calming effect, and also alert the animals that the stockperson is approaching, which is likely to reduce their level of stress. 
Time is an essential factor when measuring stockperson actions and animal behaviours at a slaughter plant. Clearly, short handling times and few negative stockperson-animal interactions are generally beneficial for AW. We believe that a sufficient number of properly trained staff and a process speed adapted to the design and technical constraints of the plant is probably important to achieve this. Logically, long handling times will give the stockpersons and animals more time to perform such actions/behaviours, thus possibly contributing to high total counts. For instance, improper plant design will probably result in long handling times and high counts. On the other hand, a low line speed means fewer stockperson actions and animal behaviours associated with poor AW per time unit because the animals are less stressed, although handling times will be longer. Coleman et al. (2012) found that the pressures imposed on abattoir stockpersons by a perceived lack of control over their actions and perceived time constraints were associated with frequent use of forceful handling actions. Thus, if long handling times follow from a deliberately low line speed, it may in fact contribute to improved AW. This raises the question whether measurements of actions and behaviours should be expressed in terms of the total number of actions/behaviours per animal (counts), or the number of actions/behaviours per animal and time unit (counts per time). We suggest that action and behaviour counts are relevant measures of the total AW impact in the section of the driveway where observations are done. In contrast, counts per time represent the average AW impact per time in the same section and they estimate the risk to an animal of receiving or displaying an action/behaviour. In either case, information about the time per animal is needed to interpret the data correctly. We consequently chose to present action and behaviour counts, as well as observation times per animal at each plant. An additional advantage of counts is that they are simpler to grasp conceptually, which makes the results more comparable to other studies such as Grandin (1998a) and Hemsworth et al. (2011).

Apart from the line speed and animal handling routines, the length and design of the driveway will influence the counts of stockperson actions and animal behaviours received/displayed at the slaughter plant. Complete measurements of the total AW impact at an abattoir require observations all the way from unloading to unconsciousness, including the unloading bay, lairage, driving race, stun box, and complete bleed-out. In this study we focussed on the driving to the stun area and stunning. For practical reasons, it was not possible to observe the animals in the whole driving race; instead a pre-defined section of the race was chosen at each slaughter plant, where reliable observations of animals and stockpersons could be made. The observed section cannot be regarded as representative for the whole driving race, but it included the part of the race leading into the stun box, where most stockperson-animal interactions were expected to take place. At three of the plants, solid walls and gates made observations impossible in the very last part of the race. According to our experience from other studies, this is precisely where cattle sometimes have to be driven forcefully to make them enter the stun box. Consequently, the presented counts give a fair but somewhat limited picture of actions and behaviours related to negative AW at the studied plants. This is likely to be a common problem in observational studies at commercial slaughter, albeit rarely, if ever, acknowledged in previous publications.

Three researchers performed the recordings of stockperson actions. Although measures were taken to secure standardised recordings, it was not possible to test the agreement between and within observers. The distribution of plants and animals differed between observers due to practical considerations; hence there is a risk that differences between observers introduced some bias. In the negative-binomial models of behaviour/action counts and animal welfare scores such observer effects, if existing, were probably largely included in the estimated effect of slaughter plant.

A Hawthorne observer effect (Homans, 1999) might have influenced the observed counts, implying that the stockpersons adapted their handling to what they assumed was expected of 
them. Being subjects of a scientific study, the stockpersons may have wanted to do the best they could, refraining from taking any extreme actions. The observers were clearly visible to the stockpersons who, in most cases, knew when observations were made. However, a general observation was that the stockpersons rapidly got used to being observed, and examples of rough handling were in fact seen.

\section{Conclusions}

At least $64 \%$ of the cattle slaughtered at four Swedish abattoirs displayed/received one or more of the recorded behaviours/actions indicative of impaired AW, and at least 34\% displayed/received behaviours/actions associated with severely compromised AW. These data show that high numbers of cattle are slaughtered in largescale plants under sub-optimal conditions. The counts of most behaviours related to negative AW varied considerably between plants, which underlines the importance of abattoir design and animal handling routines to secure good AW. Adult bulls displayed considerably more of such behaviours than dairy cows, beef cows and heifers/bullocks, indicating poorer pre-slaughter AW for the bulls.

\section{Acknowledgements}

The authors thank the Swedish Research Council for Environment, Agricultural Sciences and Spatial Planning for funding this study. The funding body was not involved in the study design, in the collection, analysis or interpretation of data, in the writing of this paper, or in deciding to submit the paper for publication. We acknowledge the cooperation and hospitality of all participating slaughter plants. We also wish to extend our thanks to Amelie Gamble and Henrik Lerner who contributed greatly in the planning and data collection phases, and to Gill Widell, Ingela Krantz, Bo Algers, Sophie Atkinson and Jenny Yngvesson for valuable comments.

\section{References}

Algers, B., Anil, H., Blokhuis, H., Fuchs, K., Hultgren, J., Lambooij, B., Nunes, T., Paulsen, P., Smulders, F., 2009. Final Report on Project to Develop Animal Welfare Risk Assessment Guidelines on Stunning and Killing. Project developed on the proposal CFP/EFSA/AHAW/2007/01. Swedish Univ. Agric. Sci., Skara, Sweden, http://www.efsa.europa.eu/en/supporting/pub/11e.htm (accessed 26 Oct. 2013).

Atkinson, S., Velarde, A., Algers, B., 2013. Assessment of stun quality at commercial slaughter in cattle shot with captive bolt. Anim. Welfare 22, 473-481.

Bourguet, C., Deiss, V., Gobert, M., Durand, D., Boissy, A., Terlouw, E.M.C., 2010. Characterising the emotional reactivity of cows to understand and predict their stress reactions to the slaughter procedure. Appl. Anim. Behav. Sci. 125, 9-21.

Bourguet, C., Deiss, V., Tannugi, C.C., Terlouw, E.M.C., 2011. Behavioural and physiological reactions of cattle in a commercial abattoir: relationships with organisational aspects of the abattoir and animal characteristics. Meat Sci. 88, 158-168.

Coleman, G.J., McGregor, M., Hemsworth, P.H., Boyce, J., Dowling, S., 2003. The relationship between beliefs, attitudes and observed behaviours of abattoir personnel in the pig industry. Appl. Anim. Behav. Sci. 82, 189-200.

Coleman, G.J., Rice, M., Hemsworth, P.H., 2012. Human-animal relationships at sheep and cattle abattoirs. Anim. Welfare 21 (Suppl. 2), 15- 21.

Food Chain Evaluation Consortium, 2007. Study on the stunning/killing practices in slaughterhouses and their economic, social and environmental consequences. In: Final 
Report, Part I: Red Meat. Civic Consulting-Agra CEAS Consulting-Bureau van Dijk-Arcadia International.

Gouveia, K.G., Ferreira, P.G., Roque de Costa, J.C., Vaz-Pires, P., Martins da Costa, P., 2009. Assessment of the efficiency of captive-bolt stunning in cattle and feasibility of associated behavioural signs. Anim. Welfare 18, 171-175.

Grandin, T., 1997. The design and construction of facilities for handling cattle. Livest. Prod. Sci. 49, 103-119.

Grandin, T., 1998a. Objective scoring of animal handling and stunning practices at slaughter plants. JAVMA 212, 36-39.

Grandin, T., 1998b. The feasibility of using vocalization scoring as an indicator of poor welfare during cattle slaughter. Appl. Anim. Behav. Sci. 56, 121-128.

Grandin, T., 2007. Handling and welfare of livestock in slaughter plants. In: Grandin, T. (Ed.), Livestock Handling and Transport. CABI Publ., Wallingford, UK, pp. 329-353.

Grandin, T., 2010. Auditing animal welfare at slaughter plants. Meat Sci. 86, 56-65.

Grandin, T., 2012. 2011 Restaurant Animal Welfare and Humane Slaughter Audits in U.S. Federally Inspected Beef and Pork Slaughter Plants, http://www.grandin.com/ (accessed 26 Oct. 2013).

Grandin, T., 2013. Making slaughterhouses more humane for cattle, pigs, and sheep. Annu. Rev. Anim. Biosci. 2013, 491-512.

Gregory, N.G., Lee, C.J., Widdicombe, J.P., 2007. Depth of concussion in cattle shot by penetrating captive bolt. Meat Sci. 77, 499-503.

Gregory, N., Shaw, F., 2000. Penetrating captive bolt stunning and exsanguination of cattle in abattoirs. J. Appl. Anim. Welfare Sci. 3, 215-230.

Hemsworth, P.H., 2003. Human-animal interactions in livestock production. Appl. Anim. Behav. Sci. 81, 185-198.

Hemsworth, P.H., Coleman, G.J., 1998. Human-livestock interactions: the stockperson and the productivity and welfare of intensively farmed animals. CABI Publ., Wallingford, UK.

Hemsworth, P.H., Rice, M., Karlen, M.G., Calleja, L., Barnett, J.L., Nash, J., Coleman, G.J., 2011. Human-animal interactions at abattoirs: relationships between handling and animal stress in sheep and cattle. Appl. Anim. Behav. Sci. 135, 24-33.

Homans, G.C., 1999. The western electric researches. In: Matteson, M.T., Ivancevich, J.M. (Eds.), Management and Organizational Behavior Classics. Irwin/McGraw-Hill, Boston, MA, USA.

Jarvis, A.M., Selkirk, L., Cockram, M.S., 1995. The influence of source, sex class andpreslaughter handling on the bruising of cattle at two slaughterhouses. Livest. Prod. Sci. 43, 215-224.

Kilgour, R., Dalton, C., 1984. Livestock Behaviour, a Practical Guide. Westview Press, Boulder, CO, USA.

Lensink, B.J., Boivin, X., Pradel, P., Le Neindre, P., Veissier, I., 2000a. Reducing veal calves' reactivity to people by providing additional human contact. J. Anim. Sci. 78, 1213-1218.

Lensink, B.J., Fernandez, X., Boivin, X., Pradel, P., Le Neindre, P., Veissier, I., 2000b. The impact of gentle contacts on ease of handling, welfare and growth of calves and on quality of veal meat. J. Anim. Sci. 78, 1219-1226.

Probst, J.K., Hillmann, E., Leiber, F., Kreuzer, M., Spengler Neff, A., 2013. Influence of gentle touching applied few weeks before slaughter on avoidance distance and slaughter stress in finishing cattle. Appl. Anim. Behav. Sci. 144, 14-21.

Probst, J.K., Spengler Neff, A., Leiber, F., Kreuzer, M., Hillmann, E., 2012. Gentle touching in early life reduces avoidance distance and slaughter stress in beef cattle. Appl. Anim. Behav. Sci. 139, 42- 49. 
Strappini, A.C., Metz, J.H.M., Gallo, C.B., Kemp, B., 2009. Origin and assessment of bruises in beef cattle at slaughter. Animal 3, 728- 736.

Swedish Board of Agriculture, 2013. Statistics Database. Swedish Board of Agriculture, Sweden, http://www.jordbruksverket.se/ (accessed 26 Oct. 2013).

Terlouw, E.M.C., Arnould, C., Auperin, B., Berri, C., Le Bihan-Duval, E., Deiss, V., Lefèvre, F., Lensink, B.J., Mounier, L., 2008. Pre-slaughter conditions, animal stress and welfare: current status and possible future research. Animal 2, 1501-1517.

Warner, R.D., Ferguson, D.M., Cottrell, J.J., Knee, B.W., 2007. Acute stress induced by the preslaughter use of electric prodders causes tougher beef meat. Aust. J. Exp. Agric. 47, $782-788$.

Waynert, D.F., Stookey, J.M., Schwartzkopf-Genswein, K.S., Watts, J.M., Waltz, C.S., 1999. The response of beef cattle to noise during handling. Appl. Anim. Behav. Sci. 62, 27-42.

Welfare Quality, 2009. Welfare Quality ${ }^{\circledR}$ Assessment Protocol for Cattle. Welfare Quality ${ }^{\circledR}$ Consortium, Lelystad, Netherlands (Report).

Wemelsfelder, F., Lawrence, A.B., 2001. Qualitative assessment of animal behaviour as an on-farm welfaremonitoring tool. Acta Agric. Scand. Sect. A (Suppl. 30), 21-25.

Wickman, M., 2013. Kunskap och attityder bland stallpersonal på svenska slakterier (Knowledge and Attitudes among Staff Handling Livestock at Swedish Slaughterhouses). Swedish Univ. Agric. Sci., Uppsala, Sweden, Graduation work.

Von Wenzlawowicz, M., von Holleben, K., Eser, E., 2012. Identifying reasons for stun failures in slaughterhouses for cattle and pigs: a field study. Anim. Welfare 21, 51-60.

Vuong, Q., 1989. Likelihood ratio tests for model selection and non-nested hypotheses. Econometrica 57, 307-333.

Yeates, J.W., Main, D.C.J., 2008. Assessment of positive welfare: a review. Vet. J. 175, 293300 . 